\title{
PRODUÇÃO DE BIOTECNOLÓGICA DE BUTANOL
}

Erlon Lopes PEREIRA ${ }^{1}$

Thalita Cardoso NEVES ${ }^{2}$

\begin{abstract}
${ }^{1}$ Departamento de Química. Setor de Engenharia Química. Universidade Federal de Viçosa. Campus: Viçosa-MG. CEP: 36570-900. e-mail: erlon.pereira@ufv.br/erlonlopes@gmail.com
\end{abstract}

${ }^{2}$ Universidade Federal de Viçosa/Departamento de Química. thalita.neves@ufv.br

Recebido em: 05/07/2016 - Aprovado em: 11/09/2016 - Disponibilizado em: 18/12/2016

\begin{abstract}
RESUMO: A produção de biocombustíveis é, sem dúvidas, o principal interesse econômico e social de países que buscam eliminar a dependência do setor petroquímico. Entretanto, um dos maiores desafios é a adaptação destes combustíveis aos motores automobilísticos tradicionalmente utilizados, neste contexto o biobutanol surge como uma promessa no âmbito de biocombustíveis. O biobutanol apresenta características muito próximas à gasolina, logo não seriam necessárias quaisquer modificações nos motores e, além disso, revela-se como um combustível ambientalmente sustentável. Entretanto, ainda são necessários alguns avanços tecnológicos ligados à matéria prima, microrganismos, e biorreatores para a otimização do processo, uma vez superados estes desafios, o biobutanol será um combustível promissor para um futuro próximo.
\end{abstract}

Palavras-chave: Biobutanol. Combustível .Bioprocessos. Fermentação. Biotecnologia.

\begin{abstract}
The production of biofuels is, without doubt, the main economic and social interest of countries that are seeking to eliminate the dependence of the petrochemical industry. However, the major challenge is to adapt these fuels to the traditionally car engines, in this context biobutanol appears as a promise in the sector of biofuels. By presenting characteristics very close to gasoline would not be necessary any changes in the engines, furthermore, it is a cleaner and sustainable fuel than gasoline. However, they are still have required some technological advances linked to raw materials, microorganisms and bioreactors for process optimization, once overcome these challenges, biobutanol is a promising fuel in a near future.
\end{abstract}

Keywords: Biobutanol. Biofuels. Bioprocess. Fermentation. Biotechnology.

\section{INTRODUÇÃ̃O}

A busca por combustíveis alternativos tem sido objeto constante de estudo no atual cenário mundial, isto devido as recorrentes crises no fornecimento de petróleo e probabilidade de escassez de combustíveis fósseis, além disso, questões ambientais também têm sido propulsores para o surgimento de combustíveis menos poluentes e provenientes de fontes alternativas (VISIOLI, 2014).
De acordo com Bohlmann (2007), Louis Pasteur foi o responsável pelo primeiro relato sobre a fermentação de glicose a butanol em 1862, mas a produção industrial de biobutanol só se iniciou em 1912, com as pesquisas do Dr. Chaim Weizmann. O processo fermentativo ficou conhecido como $\mathrm{ABE}$ devido ao fato de serem produzidos três solventes simultaneamente: acetona, butanol e etanol, primeiramente foram empregados carboidratos como substrato, utilizando a 
bactéria Clostridium acetobutylicum como microrganismo fermentador,e os principais produtos foram acetona e n-butanol. Todavia, o desenvolvimento da fermentação $\mathrm{ABE}$ só atingiu a produção industrial durante a Primeira Guerra Mundial, devido a grande demanda de acetona na produção de pólvora para armamentos, neste contexto o butanol era um produto indesejado. As plantas produtivas foram instaladas em países como Estados Unidos, Canadá, África do Sul, na antiga União Soviética e em alguns países asiáticos (BOHLMANN, 2007).

Rodrigues (2011) relatou que no Brasil, durante o período do Proálcool, o butanol foi produzido a partir da conversão de etanol a butanol, por desidrogenação do etanol, gerando hidrogênio e acetaldeído, e o hidrogênioutilizado na hidrogenação do crotonaldeído, gerando butanol. Entretanto, os processos de produção de biobutanol sofreram um declínio, devido ao aumento dos preços do melaço, matéria prima utilizada como fonte de carboidrato, e ao surgimento do processo de produção de butanol por petroquímicas, que se tornou mais atrativo financeiramente do que o fermentativo (RODRIGUES, 2011). Atualmente, o butanol é produzido principalmente por hidroformilação, ou processo oxo, neste uma oleofina, por exemplo, propileno, reage com monóxido de carbono e hidrogênio para produzir um aldeído, são produzidos isobutiraldeído e n-butiraldeído, que são convertidos a isobutanol e n-butanol. (MAGALHÃES, 2015)

De acordo com Magalhães (2015) o bioetanol e biodiesel são os combustíveis renováveis que estão sendo utilizados, entretanto existem novas alternativas emergentes que incluem etanol celulósico e biobutanol. O butanol apresenta uma série de vantagens em relação ao etanol: possui maior conteúdo energético $\left(33,81 \mathrm{MJ} \quad \mathrm{kg}^{-1}\right)$ em relação a $26,8 \mathrm{MJ} \mathrm{kg}^{-1}$ do etanol, é compatível com os sistemas de distribuição de combustível existentes para gasolina e é menos corrosivo que etanol. Além disso, por absorver menos água, as misturas de butanol e gasolina estão sujeitas a menor separação de fases do que de misturas de etanol e gasolina quando contaminadas com água, também é compatível com os motores a gasolina existentes, não sendo necessárias adaptações ou modificações. O butanol possui maior solubilidade em diesel ou gasolina em relação ao etanol, eliminando a necessidade de adição de co-solventes, além de possuir menor pressão de vapor e maior ponto de fulgor do que o etanol, caracterizando-o como mais seguro para manuseio, uso e estocagem (NEJAME, 2010).

Os biocombustíveis surgem como vias alternativas em relação aos combustíveis fósseis. As questões econômicas, sociais e ambientais levam a convergência de interesses para o desenvolvimento de tecnologias que possibilitam a produção de 
combustíveis menos agressivos ao ambiente e ao mesmo tempo economicamente viáveis. Desta forma este artigo teve como objetivo apresentar os aspectos biotecnológicos do processo produtivo relacionados à produção do biobutanol bem como expor as perspectivas tecnológicas em fase de estudo ou para um futuro próximo.

\section{REFERENCIAL TEÓRICO}

\subsection{Aplicações do butanol e seus isômeros}

O Butanol é um álcool de quarto carbonos e que possui quatro isômeros estruturais: n-butanol, isobutanol, terc-butanol e sec-butanol. O n-butanol pode ser utilizado como solvente puro e como matéria prima para fabricação de solvente de tintas e vernizes, ou para a produção de acrilato de nbutila (matéria prima utilizada na produção de polímeros e emulsões para tintas de construção civil). $\mathrm{O}$ isobutanol pode ser usado como solvente, na preparação de plastificantes, agentes de flotação ou na produção de acetato de isobutila como agente flavorizante. O terc-butanol e sec-butanol são menos consumidos, mas encontram aplicação como solventes, desnaturantes para etanol, e removedores de tintas. (MASCAL, 2012)

\subsection{Matérias-primas}

Villela Filho (2011) explica que as matérias primas para a produção de butanol são basicamente as mesmas utilizadas para a produção de outros biocombustíveis (primeira e segunda geração).

De acordo com Balat e Balat (2009), as matérias primas tradicionais para a produção dos combustíveis de primeira geração são os carboidratos do milho, da cana de açúcar e da beterraba. Estas matérias primas são consideradas facilmente fermentáveis por possuírem o carboidrato prontamente disponível, sem a necessidade de pré-tratamento ou hidrolise.

Ezeji e Blaschek (2008) mencionam que as matérias primas utilizadas na produção de combustíveis de segunda geração são os hidrolisados de material lignocelulósico como sorgo sacarineo (PARRELLA et al, 2010), bagaço de cana de açucar (RABELO, 2010), algas (ELLIS et al, 2012), madeira e resíduos florestais e glicerol residual da produção de biodiesel (ANDRADE,2003). Estas matérias primas não são consideradas facilmente fermentáveis porque não possuem o carboidrato prontamente disponível, necessitando de pré-tratamento e/ou hidrólise antes do processo fermentativo.

No Brasil, o caldo da cana-de-açúcar vem sendo objeto de estudo enquanto matéria prima viável para a produção de butanol por ser uma fonte relativamente abundante de carboidratos solúveis fermentescíveis (VILLELA FILHO, 2011).

Raganatia et al. (2012) concluíram que os materiais lignocelulósicos como bagaços vegetais residuais são uma expectativa para o 
futuro, já que não competem diretamente com a produção de alimentos como no caso do milho e da cana de açúcar. Entretanto, os autores relatam que este tipo de material necessita de um pré-tratamento para quebra da estrutura vegetal em carboidratos, isto porque o pré- tratamento é o responsável por separar a célula vegetal em celulose, hemicelulose e lignina, e após esta etapa a celulose e/ou hemicelulose devem ser submetidas a uma etapa de hidrólise para que sejam transformadas em hexoses e pentoses, respectivamente. As bactérias do gênero Clostridium são capazes de fermentar hexoses e pentoses, o que é um diferencial em relação a outros microrganismos capazes de fermentar apenas um tipo de carboidrato (RAGANATIA et al., 2012).

Segundo Barcelos (2012), o prétratamento é realizado nos materiais lignocelulósicos com o objetivo de melhorar a eficiência da hidrólise promovendo a desorganização do complexo estrutural. O que ocorre é a quebra da lignina desfazendo a estrutura cristalina da celulose, possibilitando e facilitando o acesso à celulose e hemicelulose, uma vez que estas serão as responsáveis por dar origem aos compostos fermentáveis. A proporção teórica é de 38\% de celulose, $20 \%$ de hemicelulose e $18 \%$ de lignina. Além de facilitar o acesso aos açucares, o pré-tratamento deve evitar a degradação ou perda de glúcidos, evitar a formação de possíveis subprodutos que serão inibidores dos processos seguintes e ter uma boa relação custo beneficio, uma vez que esta etapa define grande parte dos custos do processo. (BARCELOS, 2012)

Segundo Quilhó (2011) os prétratamentos podem ser físicos, químicos ou físico-químicos. Os físicos envolvem processos mecânicos como a moagem, processos de extrusão ou de irradiação. Os físico-químicos utilizam forças mecânicas e efeitos químicos, dentre eles pode-se citar: a explosão a vapor, a explosão de fibras com amoníaco e o cozimento dos materiais com água líquida sobreaquecida. Já os tratamentos químicos envolvem a utilização de ácidos, bases ou outros reagentes químicos capazes de promover a quebra da estrutura. Há também o tratamento biológico, onde certos fungos possuem a capacidade de degradar a lignina. Entretanto, nestes processos alguns inibidores da fermentação podem ser formados, tais como ácido acético, furfural, 5hidroximetil furfural, e fenóis, sendo que quando a concentração destes é prejudicial ao processo é necessária a remoção dos mesmos por métodos de destoxificação, como a utilização de carvão ativado (WANG e CHEN, 2011.), tratamento com cal (SUN e LIU, 2012), eletrólise (QURESHI et al., 2008), extração por membrana (GRZENIA et al., 2012), extração por solventes orgânicos, pervaporação, extração com fluido supercrítico e métodos biológicos, como, por 
exemplo, o emprego de lacases (CHANDEL et al., 2007).

\section{A hidrólise é o processo responsável} por converter os glúcidos gerados no prétratamento em açucares mais simples e passiveis de fermentação. Em geral, ocorre a quebra das ligações de hidrogênio e glicosídicas, presentes na hemicelulose e celulose reduzindo-as a pentoses e hexoses. $\mathrm{O}$ processo pode ser realizado por dois modos distintos: hidrólise química ou hidrólise enzimática, a primeira promove a formação de monômeros através da exposição a um produto químico, geralmente um ácido. Já a segunda trata-se da utilização de enzimas capazes de quebrar essas ligações. A celulose é hidrolisada em moléculas de celobiose e, estas por sua vez em glicose, por enzimas denominadas celulases que são produzidas naturalmente por alguns microrganismos. Entretanto, a hidrólise da hemicelulose é promovida por enzimas diferentes das utilizadas para a celulose, isso porque as moléculas de xilano, principal componente da hemicelulose, são mais complexas quimicamente (QUILHÓ, 2011).

O Quadro 1 abaixo resume as matérias primas que podem ser utilizadas para o processo de produção de biobutanol.

Quadro 1- Matérias primas para produção de biobutanol

\begin{tabular}{|c|c|c|c|}
\hline $\begin{array}{l}\text { Matéria- } \\
\text { prima }\end{array}$ & Exemplos & Vantagens & Desvantagens \\
\hline $\begin{array}{l}\text { Resíduos } \\
\text { agrícolas ou } \\
\text { subproduto }\end{array}$ & $\begin{array}{l}\text { Bagaço, milho, palha / } \\
\text { fibra / espigas, palhas (de } \\
\text { cevada, arroz, cana-de- } \\
\text { açucar, trigo) }\end{array}$ & $\begin{array}{l}\text { Processamento de } \\
\text { açúcares fermentáveis } \\
\text { mais fácil }\end{array}$ & $\begin{array}{l}\text { Dependente da disponibilidade } \\
\text { sazonal, Variações no cultivo, } \\
\text { produtividade e qualidade, mudança } \\
\text { do uso da terra, custos de transporte } \\
\text { (baixa densidade) }\end{array}$ \\
\hline $\begin{array}{l}\text { Biomassa } \\
\text { de cultivo }\end{array}$ & Mandioca, milho & $\begin{array}{l}\text { Processamento de } \\
\text { açúcares fermentáveis } \\
\text { mais fácil. }\end{array}$ & $\begin{array}{l}\text { Competitividade com alimentos, } \\
\text { dependente da disponibilidade } \\
\text { sazonal, de variações de rendimento } \\
\text { e qualidade, e da mudança do uso da } \\
\text { terra, há necessidade de água para } \\
\text { irrigação. }\end{array}$ \\
\hline $\begin{array}{l}\text { Biomassa a } \\
\text { base de } \\
\text { madeira }\end{array}$ & $\begin{array}{l}\text { Hidrolisados de madeira } \\
\text { (Por exemplo, a partir de } \\
\text { faia, pinho, faia ou } \\
\text { cicuta). }\end{array}$ & $\begin{array}{lr}\text { Não compete } & \text { com } \\
\text { alimentos, } & \text { Boa } \\
\text { disponibilidade, } & \text { menor } \\
\text { custo com transporte. }\end{array}$ & $\begin{array}{l}\text { Upstream mais difícil, possível } \\
\text { mudança no uso indireto da terra. }\end{array}$ \\
\hline $\begin{array}{l}\text { Sub- } \\
\text { produtos } \\
\text { industriais }\end{array}$ & $\begin{array}{l}\text { Bagaço de maçã, queijo } \\
\text { soro de leite, grãos secos } \\
\text { por destilação (DDGS), } \\
\text { resíduos de batata, farelos } \\
\text { (de arroz trigo, etc), } \\
\text { melaço de soja, resíduos } \\
\text { licor de sulfito de } \\
\text { indústria de papel e } \\
\text { celulose. }\end{array}$ & $\begin{array}{l}\text { Melhor aceitação social } \\
\text { devido a melhor } \\
\text { eficiência e utilização } \\
\text { dos } \\
\text { minimização recursos, } \\
\text { resíduos, não precisa de } \\
\text { alterações no uso da } \\
\text { terra. }\end{array}$ & $\begin{array}{l}\text { Variação da disponibilidade e } \\
\text { qualidade da material, necessidade } \\
\text { de operações unitárias adicionais } \\
\text { para obter a matéria prima de } \\
\text { interesse a partir do resíduo. }\end{array}$ \\
\hline
\end{tabular}




\begin{tabular}{|c|c|c|c|}
\hline $\begin{array}{l}\text { Resíduo } \\
\text { biodegra- } \\
\text { dável } \\
\text { municipal }\end{array}$ & $\begin{array}{l}\text { Resíduos de alimentação } \\
\text { e jardins, lama de } \\
\text { tratamento de água. }\end{array}$ & $\begin{array}{l}\text { Melhor aceitação social } \\
\text { devido a melhor } \\
\text { eficiência e utilização } \\
\text { dos recursos dos } \\
\text { minimização } \\
\text { resíduos, não precisa de } \\
\text { alterações no uso da } \\
\text { terra. }\end{array}$ & $\begin{array}{l}\text { Dependente da disponibilidade } \\
\text { sazonal e qualidade variável }\end{array}$ \\
\hline
\end{tabular}

Fonte: Niemistöet al. (2013)

\subsection{Microrganismos}

Os microrganismos mais utilizados para a fermentação $\mathrm{ABE}$ são bactérias do gênero Clostridium, este é um gênero de bactérias gram-positivas e anaeróbicas.A bactéria Clostridium acetobutylicumfoi a primeira a ser utilizada durante os anos 90, e após foram sendo descobertas novas espécies que também eram capazes de realizar a fermentação como: Clostridium beijerinckii, Clostridium saccharoperbutylacetonicum e Clostridium saccharobutylicum.

A vantagem da utilização deste tipo de bactéria se encontra em sua capacidade de metabolizar diferentes fontes de carbono como hexoses: glicose, frutose, manose, sucrose, lactose, galactose, pentoses: xilose e arabinose, e fontes de amido sem a necessidade de hidrólise dos polímeros, entretanto o butanol é uma substancia tóxica para estes microrganismos. (BORZANI et al, 2001).
Tammala (2003) explica que devido ao fato que a bactéria não é capaz de tolerar elevadas concentrações de butanol no meio, técnicas de engenharia genética desde então, têm sido empregadas com o objetivo de estudar e alterar microrganismos em relação aos aspectos chaves de seu metabolismo, como mecanismos de transporte de açúcar, regulação da geração de butanol, tolerância ao butanol, inibição pelos subprodutos de degradação e produção de enzimas que atuem em etapas específicas da reação. Neste contexto, tecnologias de DNA recombinante e mutagênese tradicional têm sido utilizadas para alterar as rotas metabólicas dos microrganismos, buscando melhor eficiência no processo fermentativo.

O Quadro 2 abaixo ilustra a produção de biobutanol para diferentes matérias primas utilizando alguns dos microrganismos modificados em laboratório. 
Quadro 2- Diferentes microrganismos empregados na produção de butanol

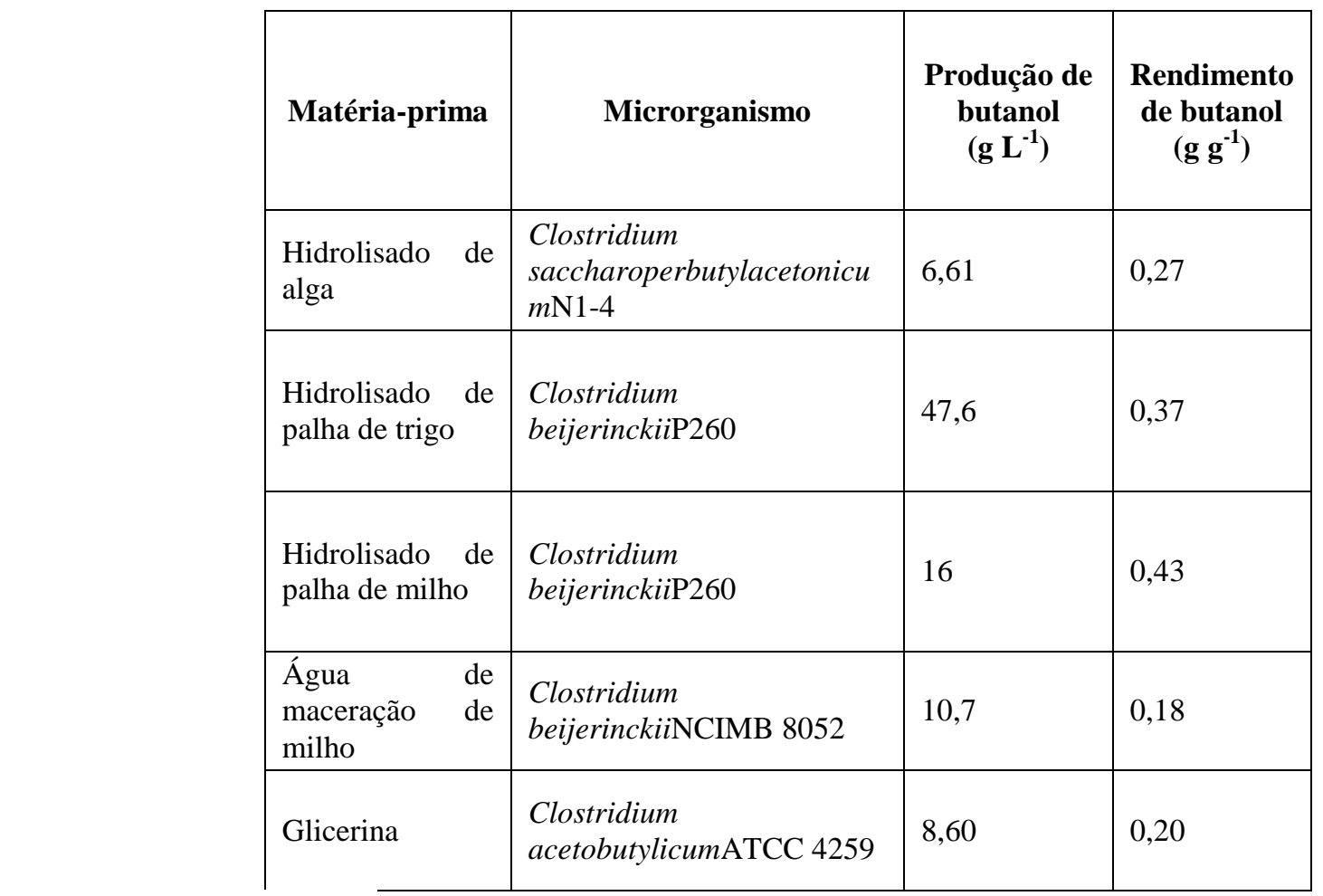

Fonte: MAITI et al. (2016)

De acordo com Natalaense (2013) estudos ligados ao uso de diferentes microrganismos, como a Eschericchia coli vem sendo realizados, mas existem dificuldades no seu emprego devido a sua limitação em relação à conversão de alguns tipos de açúcares encontrados juntamente com a glicose. O autor relatou que a empresa Gevo é uma das principais participantes no desenvolvimento e comercialização de tecnologia em biobutanol e está investindo na Eschericchia coli, já que este é um microrganismo de crescimento rápido $\mathrm{e}$ extremamente conhecido em termos de modificação genética. Também existem pesquisas em relação a leveduras utilizadas para a produção de etanol, como a Saccharomycescerevisae sendo as empresas
Butalco eButamax, grandes investidoras de pesquisas para modificações destas leveduras (NATALAENSE, 2013).

\subsection{Rotas de processos para obtenção de}

\section{Butanol}

Cascone (2009) descreve que os processos alcooquímico, termo-químico e fermentativo podem ser utilizados para a obtenção de biobutanol (Figura1). No processo fermentativo há a conversão de açúcares por meio de microrganismos fermentadores com a produção de Acetona e Butanol e Etanol (processo ABE). Existem estudos que buscam o aperfeiçoamento do processo para atingir maior produtividade, seletividade, e economia de escala. No processo alcoolquímico o butanol é obtido por síntese de Guerbet, neste o etanol é obtido 
pela fermentação tradicional com utilização de leveduras, e por condensação o etanol é convertido a butanol. No processo termoquímico o butanol é obtido por pirólise e gaseificação de biomassa, são obtidos diversos produtos neste processo, o butanol é um deles. As rotas mais prováveis para desenvolvimento de biobutanol em curto prazo são as rotas bioquímicas para fermentação (CASCONE, 2009).

Figura 1- Processos para obtenção de biobutanol

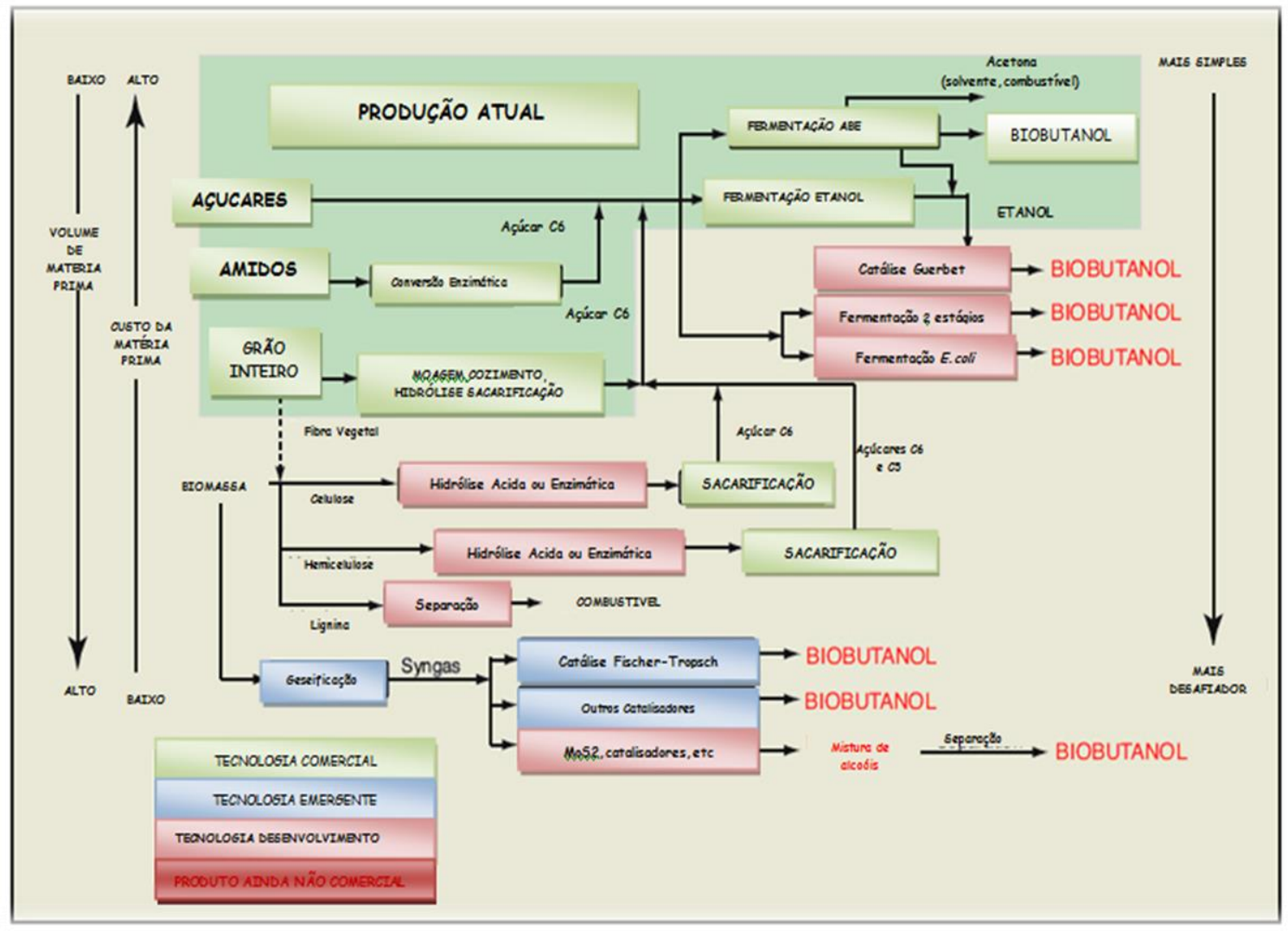

Fonte: Cascone (2009)

Kumar e Gayen (2011) afirma que o processo mais difundido para produzir biobutanol ainda é a fermentação ABE tradicional explicada no item 2.5 (JONES e WOODS, 1986). Entretanto este processo possui algumas limitações como baixa viabilidade econômica devido à dificuldade de obtenção de grandes quantidades de matéria prima a custo competitivo; baixos rendimentos, pois o butanol é tóxico aos microrganismos, e os processos de recuperação de produto ainda são ineficientes e de alto custo. (KUMAR e GAYEN, 2011)

\subsection{Fermentação ABE}

Durante uma fermentação por Clostridium acetobutylicum são observadas duas fases distintas na fermentação. $\mathrm{Na}$ primeira fase denominada acidogênese, ocorre o crescimento celular exponencial com produçãode dióxido de carbono, hidrogênio, 
ácidoacético (acetato) e ácido butírico (butirato), há uma diminuição do $\mathrm{pH}$ do meio de cultura devido aprodução dos ácidos orgânicos atingindo valores de $\mathrm{pH}$ em torno de 4,5. No momento em que a concentração de ácidos se torna suficientemente alta, o crescimento celular atinge a fase estacionária e se inicia a segunda fase da fermentação denominada solventogênese. Nesta fase os ácidos passam a ser consumidos junto com a fonte de carbono formando os solventes acetona e butanol ocorrendo um aumento do $\mathrm{pH}$ do meio de cultura devido a reassimilação dos ácidos (JONES e WOODS, 1986).

Jones e Woods (1986) acreditavam que essa transição da fase acidogênica para a solventogênica estivesse relacionada ao $\mathrm{pH}$. Atualmente Visioli (2014) afirma que a transição entre as fases está associada a concentração de ácido butírico não dissociado e não ao pH.

De acordo com BORZANI et al (2001) a via fermentativa pode resumida em um processo em que a glicose é transformada em piruvato, segundo o ciclo de EmbdenMeyerhof-Parnas. Na rota metabólica o piruvato se transforma em acetil-CoA, com liberação de $\mathrm{CO}_{2}$ e $\mathrm{H}_{2}$ e então duas moléculas de acetil-CoA formam acetoacetil-CoA e induzem a formação de ácido butirico. Este ácido é responsável por causar a queda do $\mathrm{pH}$ do meio de 5,8 a 6 para 4, estimulando a ação de enzimas que possibilitam a formação de butanol e acetona. $\mathrm{O}$ acetil-CoA se transforma em acetilfosfato pela ação de uma enzima transferase, a fosfatil-acetil-transferase, o acetilfosfato por sua vez se transforma em ácido acético pela ação da enzima acetoquinase. O butanol é obtido pela via em que o buritil-CoA dá origem ao butiril-fosfato por ação da fosfato-butiriltransferase, e este dá origem ao butirato pela ação da enzima butiratoquinase. $\mathrm{O}$ acido butírico produz butanol invertendo a reação. A acetona, por sua vez, é formada por descarboxilação do aceto-acetato, quando ocorre a ativação do mecanismo de assimilação de ácidos, onde acetato e de butirato levam a formação de acetona.

A rota metabólica descrita está detalhada na Figura 2 
Figura 2 - Rota metabólica de Clostridiumacetobutylicum

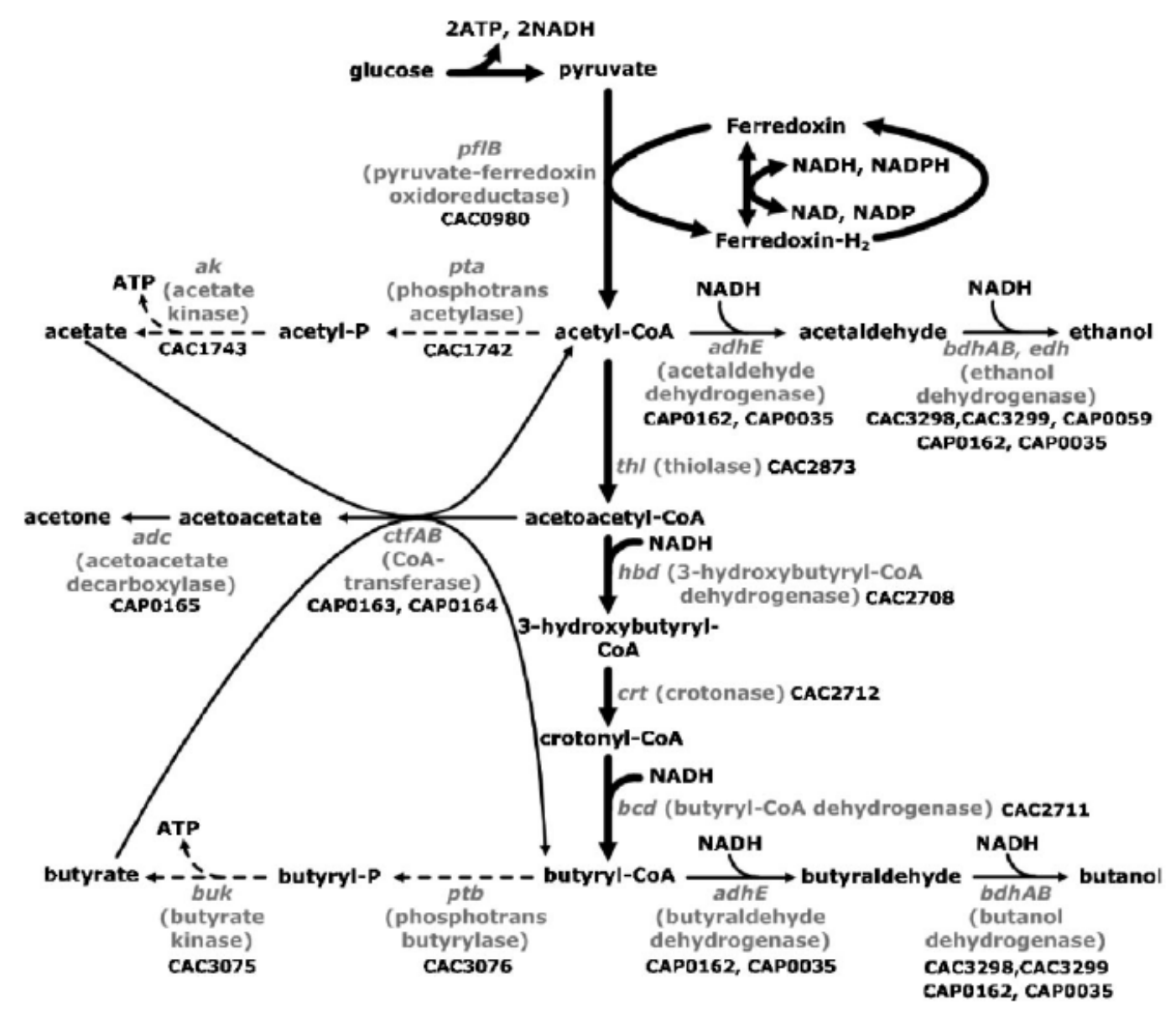

Fonte: LEE et al.(2008)

LEE et al.(2008) explicam que o ponto limitante da fermentação é a inibição da bactéria pela toxicidade dos solventes, principalmente do butanol, este solvente provoca o rompimento dos componentes fosfolipídicos da membrana aumentando a sua fluidez, sendo que o metabolismo celular é interrompido quando a concentração de butanol atinge uma concentração de aproximadamente $13 \mathrm{~g} \quad \mathrm{~L}^{-1}$. Entretanto, concentrações superiores a esta podem ser obtidas com o uso de técnicas de fermentação e separação mais avançadas bem como com o uso engenharia genética de microrganismos.

\subsection{Biorreatores para obtenção de Butanol}

Ranjan e Moholkar (2012) descrevem que o processo para produção de butanol pode ser realizado em biorreatores que operam em batelada, batelada alimentada ou de modo continuo, sendo o processo batelada o mais empregado, devido a sua simplicidade e facilidade de controle.

A fermentação em batelada consiste na utilização de um reator com agitação, revestido por uma camisa de aquecimento e resfriamento, este recebe a alimentação de substrato e nutrientes em concentrações típicas de 60 a $80 \mathrm{~g} \mathrm{~L}^{-1}$. O autor descreve o procedimento para fermentação $\mathrm{ABE}$ em 
reatores descontínuos da seguinte maneira: $\mathrm{O}$ reator é esterilizado a aproximadamente $120^{\circ} \mathrm{C}$, e após é realizado um resfriamento até aproximadamente $\quad 35-37 \quad{ }^{\circ} \mathrm{C}$, nesta temperatura é realizado o inoculo. Através de uma purga de nitrogênio ou $\mathrm{CO}_{2}$ o reator é mantido em condições anaeróbias, e o tempo para fermentação é de $48 \mathrm{~h}$ a $72 \mathrm{~h}$, sendo que ao atingir uma concentração de $20 \mathrm{gL}^{-1}$ de butanol, o crescimento celular cessa e consequentemente a fermentação chega ao fim. A massa celular e os sólidos são separados da solução por centrifugação, e a porção líquida é enviada para a destilação (RANJAN e MOHOLKAR, 2012).

$\mathrm{Na}$ fermentação em batelada alimentada o reator é iniciado no modo batelada com baixa concentração de substrato e conforme o substrato é consumido, são realizadas cargas adicionais mantendo o nível abaixo da concentração tóxica. Já a fermentação contínua consiste em um reator que pode ser empregado um único estágio, onde há alimentação de substrato e retirada contínua de solvente, ou podem ser empregados uma série de reatores em vários estágios, a fim de contemplar os estágios da fermentação: acidogênese e solventogênese. Entretanto, neste tipo de fermentação são encontradas dificuldades devido a flutuação dos níveis de produção. (RANJAN e MOHOLKAR,2012)

Kumar e Gayen (2011) cita que existem estudos baseados em um aumento da produtividade do processo utilizando reatores contínuos manipulando as células e concentrações de solvente para que não atinjam concentrações tóxicas aos microrganismos, dentre estas técnicas emergentes podem-se destacar os reatores contínuos de célula imobilizada e os reatores contínuos com membranas.

Os reatores contínuos de célula imobilizada consistem em um processo em que o substrato é introduzido em um reator tubular ao fundo e a recuperação de solvente acontece no topo, sendo que as células de microrganismos são imobilizadas em blocos de argila por adsorção, este processo permite utilização de alta concentração de microrganismos e alta produtividade do reator, a produtividade chega a ser 40 a 50 vezes maior que nos sistemas contínuos convencionais. Os reatores contínuos com membranas são iniciados no modo batelada, nesta etapa ocorre o crescimento celular e antes que fase estacionária seja atingida, o caldo de fermentação é direcionado para uma membrana, nesta a solução aquosa passa enquanto as células ficam retidas, a alimentação do reator e o permeado são contínuos e uma taxa constante é mantida no reator. Entretanto, ocorre a saturação das membranas, ao longo do processo, dessa forma os reatores contínuos apresentam dificuldades de implementação, aumento de escala e manutenção. 
O Quadro 3 abaixo mostra os rendimentos para fermentação $\mathrm{ABE}$ em relação a diferentes matérias primas, microrganismos e processos produtivos.

Quadro 3 - Rendimento para fermentação ABE para diferentes processos produtivos

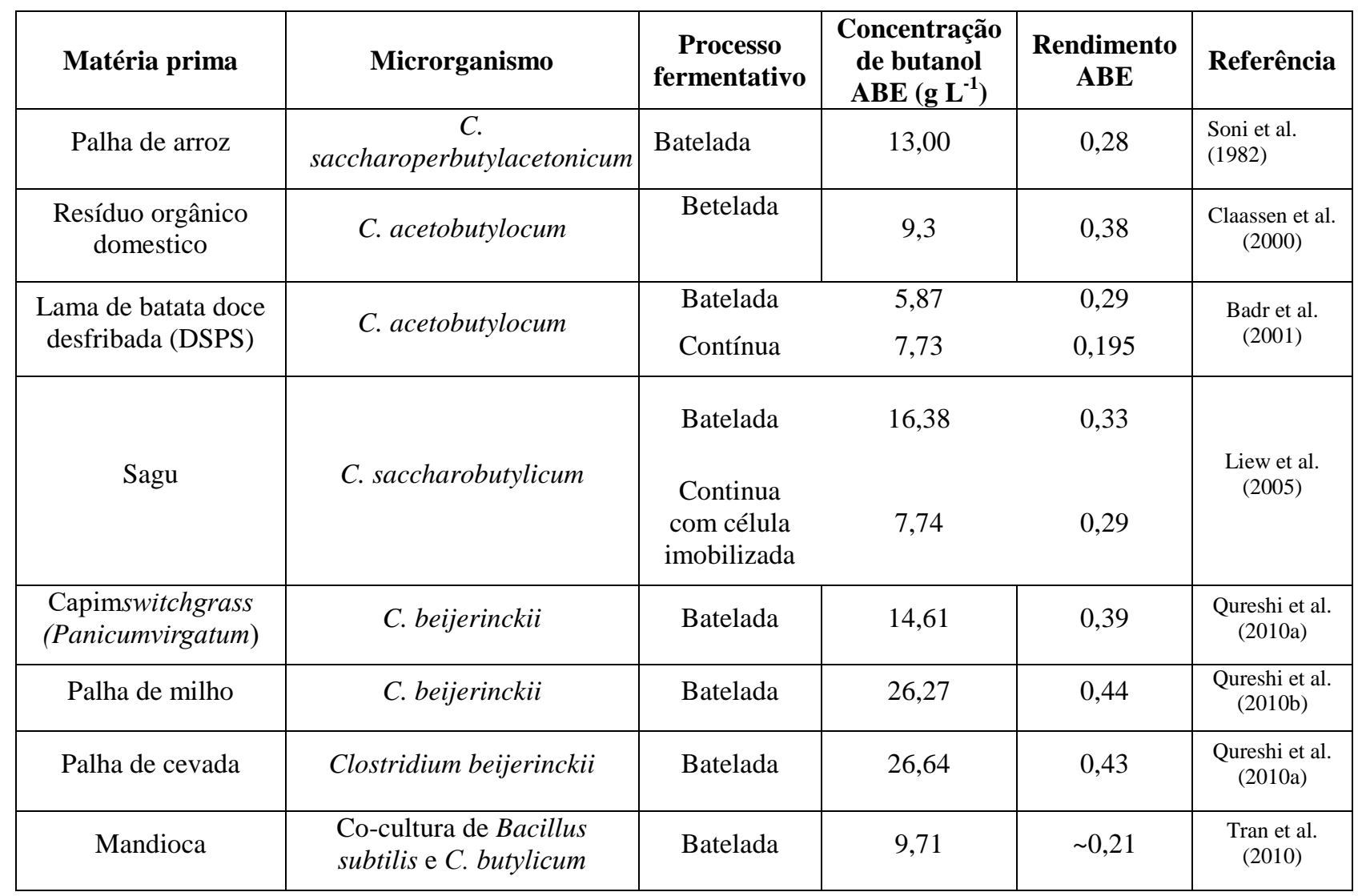

Fonte: LIU et al. (2013)

Maitiet al (2016) demonstram através de estudos mais recentes que ainda não foram atingidos rendimentos de fermentação $\mathrm{ABE}$ muito superiores aos relatados anteriormente. Em seu estudo os autores utilizam como substratos resíduos agrícolas industriais: Resíduo líquido de cervejaria (Brewery liquidwast: BLW), Resíduo líquido de industria de amido (Starch industry wastewater: SIW) e Lama de bagaço de maça de ultrafiltração (Apple pomance ultrafiltration sludge: APUS), estes foram prétratados com acido sulfúrico diluído e posteriormente, o hidrolisado passou por uma etapa de destoxificação para redução da concentração de inibidores. O microrganismo utilizado foi Clostridium beijerinckii NRRL B-466. Para análise do desempenho da produção de butanol foram realizados cinco processos produtivos em batelada: (1) controle de glicose $30 \mathrm{~g} \mathrm{~L}^{-1}$, (2) soluções das biomassas sem pré-tratamento, (3) soluções de biomassa pré-tratadas com acido, (4) soluções de biomassa pré-tratas com ácido e suplementadas com glicose, (5) soluções com diferentes concentrações de biomassa 
suplementadas com $30 \mathrm{~g} \mathrm{~L}^{-1}$ de glicose $\mathrm{O}$ estudo concluiu que o máximo de butanol foi obtido utilizando o resíduo industrial de amido, sendo que após 96 horas de fermentação do hidrolisado suplementado com $3 \%$ de glicose foram produzidos
$11,04 \mathrm{gL}^{-1}$ de butanol, com um rendimento de $0,27\left(\mathrm{~g} \mathrm{~g}^{-1}\right)$. Para o resíduo de cervejaria a produção foi de $8,06 \mathrm{~g} \mathrm{~L}^{-1}$ e para a lama de maça 9,3 g $\mathrm{L}^{-1}$. Outros resultados experimentais importantes são mostrados no Quadro 4 a seguir.

Quadro 4 - Resultados experimentais de Maiti et al. (2016)

\begin{tabular}{|c|c|c|c|c|}
\hline \multirow[b]{2}{*}{ Preparação da biomassa } & \multirow{2}{*}{$\begin{array}{l}\text { Parâmetros } \\
\text { analisados }\end{array}$} & \multicolumn{3}{|c|}{ Biomassa } \\
\hline & & $\begin{array}{l}\text { Resíduo líquido } \\
\text { de cervejaria }\end{array}$ & $\begin{array}{l}\text { Lama de bagaço de } \\
\text { maça de } \\
\text { ultrafiltração }\end{array}$ & $\begin{array}{l}\text { Resíduo líquido de } \\
\text { indústria de } \\
\text { amido }\end{array}$ \\
\hline Sem pré-tratamento & $\begin{array}{l}\text { Concentração de } \\
\text { butanol }\left(\mathrm{g} \mathrm{L}^{-1}\right)\end{array}$ & $\begin{array}{c}\text { Sem } \\
\text { concentrações } \\
\text { significativas } \\
\end{array}$ & $\begin{array}{l}\text { Sem concentrações } \\
\text { significativas }\end{array}$ & $\begin{array}{c}\text { Sem concentrações } \\
\text { significativas }\end{array}$ \\
\hline $\begin{array}{c}\text { Pré-tratamento e } \\
\text { destoxificação }\end{array}$ & $\begin{array}{l}\text { Concentração de } \\
\text { butanol }\left(\mathrm{g} \mathrm{L}^{-1}\right)\end{array}$ & $1,8 \pm 0,21$ & $1,4 \pm 0,32$ & $4,68 \pm 0,14$ \\
\hline \multirow{4}{*}{$\begin{array}{c}\text { Pré-tratamento, destoxificaçãoe } \\
\text { suplemento de } \\
3 \%\left(\mathrm{~m} \mathrm{v}^{-1}\right) \text { de glicose }\end{array}$} & $\begin{array}{l}\text { Total de açucares } \\
\left(\mathrm{g} \mathrm{L}^{-1}\right)\end{array}$ & $32,15 \pm 1,1$ & $39,1 \pm 1,6$ & $40,4 \pm 1,5$ \\
\hline & $\begin{array}{l}\text { Rendimento de } \\
\text { butanol }\left(\mathrm{g} \mathrm{g}^{-1}\right)\end{array}$ & $0,25 \pm 0,06$ & $0,239 \pm 0,01$ & $0,270 \pm 0,02$ \\
\hline & $\begin{array}{l}\text { Rendimento de } \\
\text { acetona }\left(\mathrm{g} \mathrm{g}^{-1}\right)\end{array}$ & $0,046 \pm 0,01$ & $0,169 \pm 0,08$ & $0,173 \pm 0,05$ \\
\hline & $\begin{array}{l}\text { Rendimento total } \\
\text { da } \operatorname{ABE}\left(\mathrm{g} \mathrm{g}^{-1}\right)\end{array}$ & $0,328 \pm 0,01$ & $0,456 \pm 0,10$ & $0,465 \pm 0,01$ \\
\hline
\end{tabular}

Fonte: Maitiet al (2016)

Os autores fornecem gráficos de concentração de solvente por tempo de fermentação e um balanço de massa referente ao carbono. Estes resultados são mostrados nas Figuras 3 e 4 a seguir, respectivamente. 
Figura 3- Fermentação ABE por Clostridium beijerinckii NRRL B-466 para diferentes biomassas e hidrolisado suplementado com 3\% de glicose. (a) Controle de glicose. (b) Resíduo líquido de indústria de amido. (c) Lama de bagaço de maça de ultrafiltração. (d) Resíduo líquido de cervejaria.
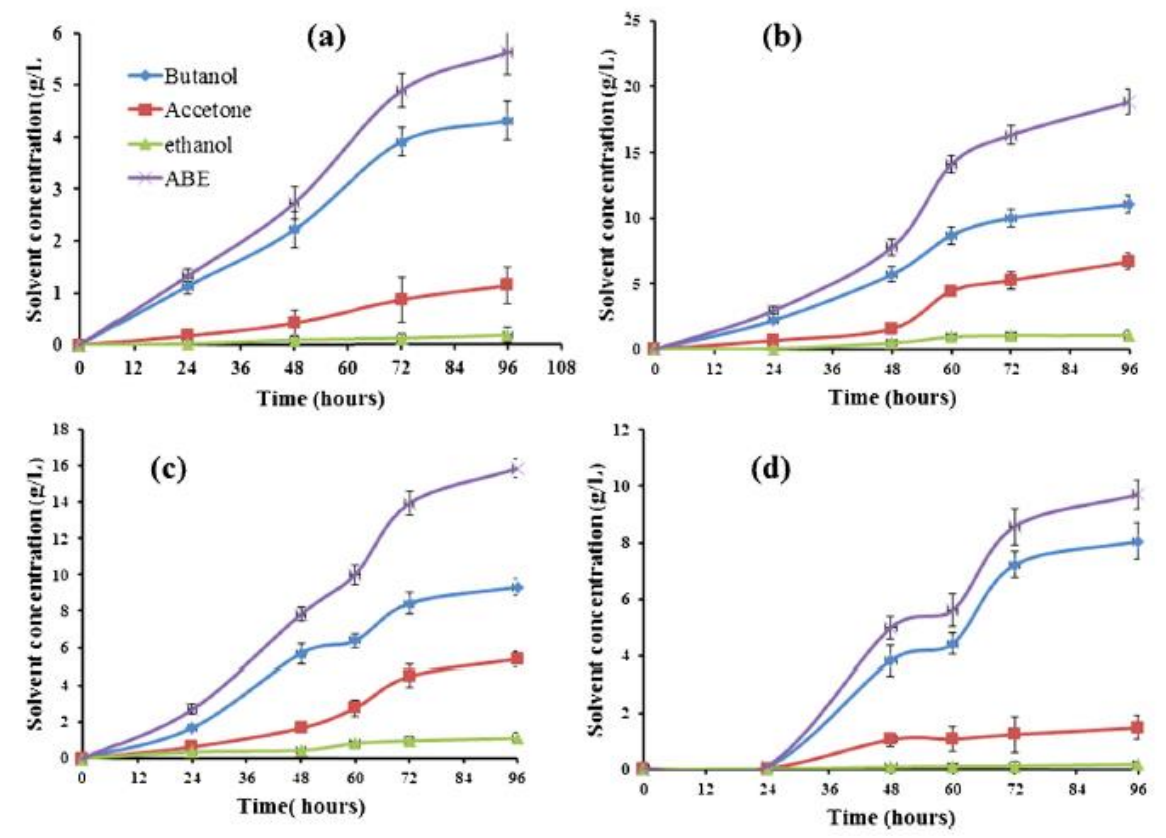

Fonte: Maiti et al (2016)

Figura 3 - Distribuição do uso do carbono para cada biomassa. (a) Controle de glicose. (b) Resíduo líquido de cervejaria (c) Lama de bagaço de maça de ultrafiltração (d) Resíduo líquido de indústria de amido.

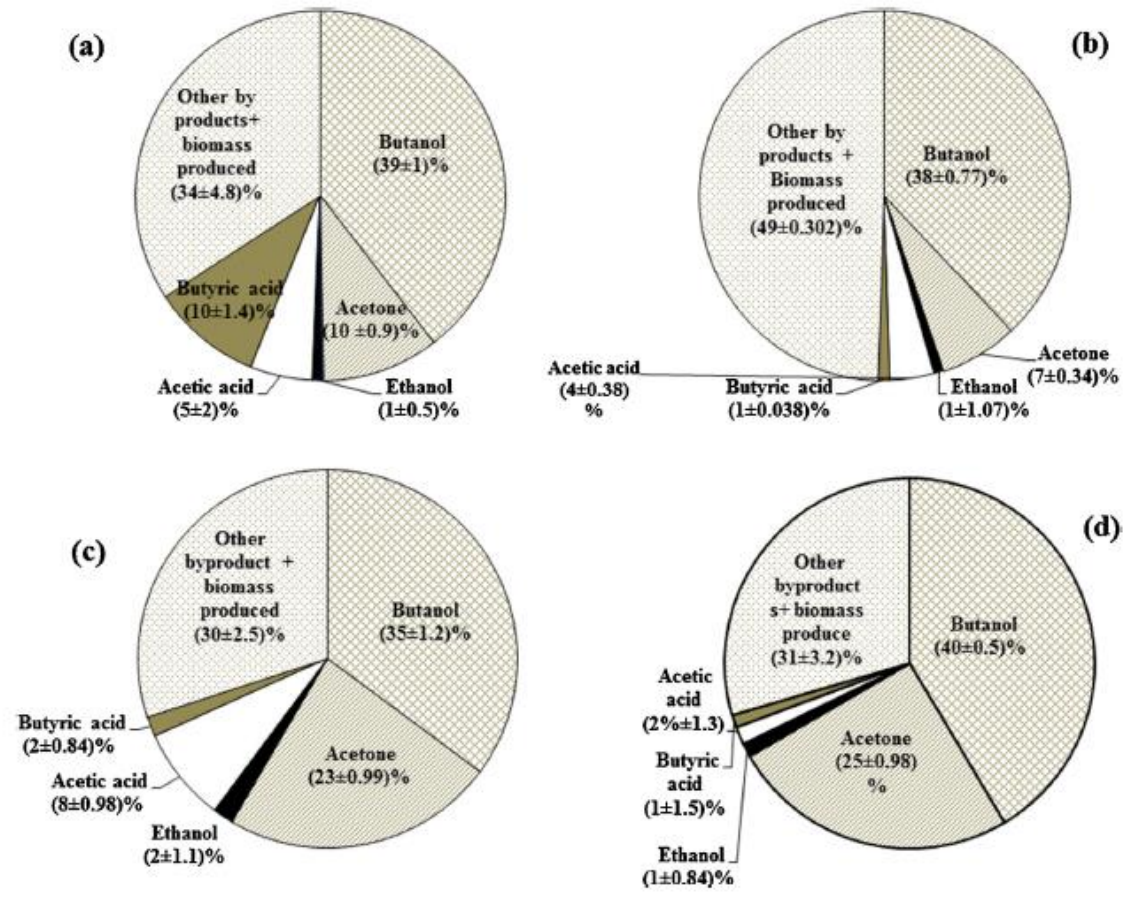

Fonte: Maiti et al. (2016)

Maiti et al (2016) concluem através da análise do balanço de massa de carbono que todas as biomassas em estudo podem ser utilizadas para produção de biobutanol, 
entretanto apesar de o resíduo de amido apresentar o melhor rendimento, o resíduo de cervejaria seria o mais interessante devido a menor produção de acetona e maior seletividade do processo. Dessa forma a capacidade de produzir solventes de alto valor agregado a partir destas matérias primas tem efeito positivo no potencial de produção industrial.

Dessa forma a produção de biobutanol a partir de biomassa residual é um processo que vem sendo estudado por diversas linhas de pesquisa, e apesar de ainda não terem sido alcançados altos rendimentos, a produção deste biocombustível se revela como uma boa alternativa para o reaproveitamento de resíduos industriais e produção de solventes de alto valor agregado.

\subsection{Separação dos produtos da} fermentação

JIN et al (2011) descrevem que o processo utilizado atualmente para separação do biobutanol combustível é a destilação, entretanto este processo não é economicamente viável para o butanol devido as baixas concentração deste em água, desta forma, têm sido estudados novas operações para retirar os solventes do processo de forma a reduzir os custos relacionados a destilação final. A possibilidade de remover o solvente continuamente do caldo seria uma destas formas, além de contornar o problema da toxicidade do butanol aos microrganismos.
Dentre as técnicas que estão sendo estudadas pode-se citar a extração por gás de arraste, a extração líquido-líquido, perstração e a pervaporação

A extração por gás de arraste consiste no arraste do solvente por gases, podeutilizar nitrogênio ou gás carbônico como gás de arraste, ou então os próprios gases da fermentação $\left(\mathrm{CO}_{2}\right.$ e $\left.\mathrm{H}_{2}\right)$ podem ser recuperados e borbulhados no reator, os solventes arrastados são posteriormente recuperados por condensação, enquanto o gás de arraste é reciclado e enviado novamente ao reator. Ezejiet al (2004) utilizou o processo de araste para separação dos solventes em um processo batelada utilizando glicose como substrato produzindo $233 \mathrm{~g} \mathrm{~L}^{-1}$ de solvente com um rendimento de $0,47\left(\mathrm{~g} \mathrm{~g}^{-1}\right)$, já em processo continuo $460 \mathrm{~g} \mathrm{~L}^{-1}$ de solvente foram obtidos com um rendimento de $0,40\left(\mathrm{~g} \mathrm{~g}^{-1}\right)$. (EZEJI et al., 2004a; EZEJI et al.,2004b)

Mariano et al (2012) trata da remoção do solvente durante a fermentação, onde é que utilizado vácuo para reduzir a pressão do sistema possibilitando a ebulição do butanol e a recuperação do azeótropo formado pela água e butanol. Segundo os autores a concentração de ABE na corrente de recuperação foi aumentada de $15,7 \mathrm{~g} \mathrm{~L}^{-1}$ para até33 $\mathrm{g} \mathrm{L}^{-1}$, concluindo que a integração do vácuo ao biorreator resultou em aumento de produtividade $\mathrm{ABE}$ em $100 \%$ e a completa utilização de glicose. 
Qureshi e Blaschek (1999) descrevem que extração líquido-líquido, consiste na adição de um solvente orgânico, como por exemplo, decanol, ao caldo de fermentação. Como o butanol possui mais afinidade pela fase orgânica do que pela aquosa, este migra facilmente para a fase orgânica. Após a extração, o butanol é obtido puro por destilação. Líquidos iônicos também podem ser utilizados como extratores, e representam uma vantagem na medida em que reduzem a utilização de extratores tóxicos para os microrganismos.

$\mathrm{Na}$ Perstração o caldo de fermentação e o líquido extrator são separados por uma membrana e um vácuo é aplicado no lado do permeado, através da membrana as duas fases imiscíveis podem trocar butanol; uma vez que não há contato entre as duas fases, a toxicidade do líquido extrator não afeta $o$ caldo de fermentação. A difusão de outros solventes também pode ser controlada seletivamente pela membrana, aumentando a concentração de butanol.

A Pervaporação também faz uso de membranas, nesta o solvente permeia pela membrana e é recuperado por destilação, sendo que a eficiência do processo é dependente da seletividade da membrana (JIN et al 2011). Evans e Wang demonstram que a concentração de solvente produtividade são aumentadas de $24,2 \mathrm{~g} \mathrm{~L}^{-1}$ e $0,34 \mathrm{~g}(\mathrm{~L} \mathrm{~h})^{-1}$ para $32,8 \mathrm{~g} \mathrm{~L}^{-1}$ e $0,5 \mathrm{~g}(\mathrm{~L} \mathrm{~h})^{-1}$ com a utilização de pervaporação (Evans e Wang, 1988). Groot et al. (1984) utilizaram a pervaporação aplicada sobre a fermentação em batelada alimentada ea produtividade e concentração do solvente atingiram 0,98 $\mathrm{g}(\mathrm{L} \mathrm{h})^{-1}$ e $16,51 \mathrm{~g} \mathrm{~L}^{-1}$ respectivamente (Groot et al.,1984).

Estudos comparativos realizados por Qureshi et al. (2005) relataram sobre os gastos energéticos relacionados à recuperação de butanol a partir do caldo de fermentação por técnicas de adsorção, arraste de gás, extração líquido-líquido e pervaporação. Os autores concluiram que a adsorção usando silicalita é o método mais eficiente de energia (8,16 $\mathrm{MJ} \mathrm{kg}^{-1}$ de 1-butanol). Oudshoorn et al (2009) relataram que técnicas de adsorção e pervaporação são energeticamente eficientes, e preveem uma demanda energética menor que $4 \mathrm{MJ}$ por kg de butanol.

Magalhães (2015) afirma que a produção industrial de butanol pela fermentação $\mathrm{ABE}$ ainda não totalmente viável, devido ao baixo rendimento encontrado, alto tempo de fermentação e custo de recuperação do produto, problemas com a instabilidade genética e degeneração da linhagem dos Clostridios e alto custo dos substratos utilizados como matéria primas. Uma vez minimizados estes desafios a produção de biobutanol representará um avanço tecnológico em se tratando de biocombustíveis. Existem algumas empresas que já fazem uso de bioprocessos para produção de butanol, o Quadro 5 a seguir 
ilustra estas empresas e seus respectivos

processos produtivos.

Quadro 5 - Empresas que investem em biobutanol

\begin{tabular}{|c|c|c|c|c|c|}
\hline Empresa & Microrganismo & Estratégia & Molécula & $\begin{array}{l}\text { Processo } \\
\text { Fermentativo }\end{array}$ & $\begin{array}{l}\text { Estratégia de } \\
\text { separação }\end{array}$ \\
\hline GEVO & E.Coli & $\begin{array}{l}\text { Microrganismo } \\
\text { geneticamente } \\
\text { modificado (GMO) }\end{array}$ & Isobutanol & Semi-contínuo & $\begin{array}{lr}\text { Remoção } & \text { a } \\
\text { vácuo in } & \text { situ } \\
\text { seguida } & \text { de } \\
\text { destilação } & \end{array}$ \\
\hline $\begin{array}{l}\text { Butamax } \\
\text { (Dupont/BP) }\end{array}$ & $\begin{array}{l}\text { Clostridia } \\
\text { E.Coli }\end{array}$ & GMO & Isobutanol & Semi-contínuo & $\begin{array}{l}\text { Remoção in } \\
\text { situ seguida de } \\
\text { destilação }\end{array}$ \\
\hline CobaltBiofuels & Clostridia & $\begin{array}{l}\text { Não GMO, acetona } \\
\text { e etanol reduzidos }\end{array}$ & n-butanol & $\begin{array}{l}\mathrm{ABE} \\
\text { modificada*, } \\
\text { contínuo }\end{array}$ & $\begin{array}{lr}\text { Remoção } & \text { com } \\
\text { vapor } & \text { e } \\
\text { destilação } & \end{array}$ \\
\hline $\begin{array}{l}\text { Green Biologics } \\
\text { (UK) }\end{array}$ & $\begin{array}{l}\text { Mistura de } \\
\text { Clostridia }\end{array}$ & $\begin{array}{l}\text { GMO de alta } \\
\text { tolerância }\end{array}$ & n-butanol & $\begin{array}{l}\text { Fermentação } \\
\text { continua }\end{array}$ & $\begin{array}{l}\text { Remoção in } \\
\text { situ seguida de } \\
\text { destilação }\end{array}$ \\
\hline ButylFuel & Clostridia & GMO e mutações & n-butanol & $\begin{array}{l}\text { Fermentação } \\
\text { continua reator } \\
\text { de dois estágios }\end{array}$ & $\begin{array}{lr}\text { Stripping } & \mathrm{e} \\
\text { reator } & \mathrm{de} \\
\text { célula } & \\
\text { imobilizada } & \end{array}$ \\
\hline $\begin{array}{l}\text { Tetra Vitae } \\
\text { (Eastman) }\end{array}$ & C.beijerinckii & $\begin{array}{l}\text { Não GMO, etanol } \\
\text { reduzido }\end{array}$ & $\begin{array}{l}\text { n-butanol e } \\
\text { acetona 2:1 }\end{array}$ & Batelada & $\begin{array}{l}\text { Extração com } \\
\mathrm{CO} 2 \text { continua } \\
\text { in situ seguida } \\
\text { de destilação }\end{array}$ \\
\hline Cathay & Clostridia & $\begin{array}{l}\text { Migrando para } \\
\text { GMO }\end{array}$ & n-butanol & $\begin{array}{lr}\text { Migrando } & \text { do } \\
\text { processo } & \mathrm{ABE} \\
\text { tradicional } & \end{array}$ & $\begin{array}{l}\text { Remoção in } \\
\text { situ }\end{array}$ \\
\hline
\end{tabular}

*ABE modificada refere-se ao processo produtivo que sofreu alguma adaptação realizada pela empresa, enquanto que $\mathrm{ABE}$ tradicional refere-se ao processo produtivo descrito na seções anteriores.

Fonte: Natalaense (2013)

\section{PERSPECTIVAS PARA O}

\section{BIOBUTANOL}

Balatet al (2009) ressalta que o biobutanol surge como um biocombustível em potencial para substituição da gasolina ou possível incorporação ao diesel, isto devido ao fato possuir elevado poder calorífico, baixo ponto de congelamento, baixa absorção de água, e não serem necessárias alterações nos motores atuais para a utilização de butanol combustível. Além disso, o butanol torna o arranque a frio mais fácil do que quando é utilizado etanol. Souza (2009) ainda destaca que existe um efeito sinérgico de butanol na biodegradação de combustíveis em solo e água, em misturas de $20 \%$ butanol/gasolina e $20 \%$ butanol/diesel.

$$
\text { Segundo Natalaense (2013) em }
$$
relação aos isômeros do butanol apenas nbutanol e isobutanol são obtidos por via fermentativa e dentre estes o isobutanol apresenta maior octanagem e propriedades mais próximas à gasolina, contribuindo para o bom desempenho dos motores. Já os outros isômeros, sec-butanol e o terc-butanol, não são produtos da via fermentativa. Quadro 6 baixo ilustra as propriedades de interesse de combustíveis em comparação ao biobutanol. 
Quadro 6 - Comparação das propriedades dos combustíveis

\begin{tabular}{|l|c|c|c|c|c|}
\hline Propriedade & Unidade & Gasolina & Diesel & Etanol & n-butanol \\
\hline Densidade & ${\mathrm{g}\left(\mathrm{cm}^{3}\right)^{-1}}^{-1}$ & $0,72-0,78$ & $0,82-0,86$ & 0,79 & 0,81 \\
\hline $\begin{array}{l}\text { Numero de } \\
\text { octano }\end{array}$ & adimensional & $80-99$ & $20-30$ & 108 & 96 \\
\hline $\begin{array}{l}\text { Viscosidade a } \\
40^{\circ} \mathrm{C}\end{array}$ & $\mathrm{mm}^{2} \mathrm{~s}^{-1}$ & $0,40-0,80$ & $1,90-4,10$ & 1,08 & 2,63 \\
\hline Ponto de fulgor & ${ }^{\circ} \mathrm{C}$ & $-40 \mathrm{a}-38$ & $65-88$ & 8 & 35 \\
\hline $\begin{array}{l}\text { Ponto de } \\
\text { ebulição }\end{array}$ & ${ }^{\circ} \mathrm{C}$ & $25-215$ & $180-370$ & 78 & 118 \\
\hline $\begin{array}{l}\text { Poder } \\
\text { calorífico }\end{array}$ & $\mathrm{MJ} \mathrm{kg}^{-1}$ & 42,7 & 42,5 & 26,8 & 33,1 \\
\hline
\end{tabular}

Fonte: Natalense (2013)

Natalaense (2013) ressalta que a incorporação de combustíveis renováveis à matriz de energética é uma meta buscada por vários países e já existem legislações ambientais que garantem a incorporação de biocombustíveis aos combustíveis fosseis. Desta forma, existe uma oportunidade de mercado para o biobutanol, seja no mercado americano para suprir o consumo interno, ou no mercado brasileiro como base exportadora para os Estados Unidos e outros países.

Franco (2015) relata que Ricardo Vellutini, presidente da Butamax/Dupont no Brasil afirma que o novo combustível será complementar ao etanol. Desde 2006 a Butamax estuda a eficiência do novo produto usando cana-de-açúcar, milho, trigo e soja como matérias-primas básicas. No Brasil, a matéria prima utilizada para o processo será cana-de-açúcar, nos Estados Unidos será principalmente o milho, e na União Europeia será o trigo. As estimativas são que, até 2022, os americanos terão uma demanda interna aproximada de 135 bilhões de litros de biocombustíveis, e $20 \%$ desse volume poderá ser biobutanol. Ainda segundo Vellutini, o foco da empresa seria vender a tecnologia de fabricação para as usinas brasileiras, onde os usineiros possam produzir etanol para o mercado interno e biobutanol para exportação. Magalhães (2015) afirma que em se tratando da viabilidade do processo, ainda são necessários avanços tecnológicos para que a produção se torne mais eficiente e economicamente viável. Ainda segundo a autora modificações genéticas de microrganismos são importantes, de maneira a torná-los mais resistentes ao produto e menos sensíveis a mutações, contaminações e degeneração. Além disso, o processo fermentativo para produção de biobutanol exige condições de assepsia rigorosas e demoradas, o que aumenta os custos dos materiais, instalações, e utilidades para conduzir a operação. 
Ainda segundo Magalhães (2015) uma das linhas de pesquisa para aumentar a eficiência do processo e contornar o problema de toxicidade do butanol aos microrganismos é a remoção contínua de solvente do meio fermentativo. Além disso, uma vez que a matéria prima é responsável por grande parte dos custos, podem ser utilizados materiais que seriam descartados pelas indústrias como materiais lignocelulósicos (bagaço de cana de açúcar ou resíduos de indústrias de papel e celulose) o que remete ao conceito de instalação de biorrefinarias nas indústrias geradoras dos resíduos, permitindo a transformação destes em produtos de maior valor agregado. Entretanto, ainda são necessários estudos em relação aos prétratamentos utilizados para disponibilização do substrato em relação aos materiais lignocelulósicos, uma vez que durante estes tratamentos ainda são gerados inibidores do processo. Também são necessários avanços em relação à tecnologia dos biorreatores, sendo que os reatores contínuos de célula imobilizada prometem aumentar a eficiência do processo e os níveis de produção, os desafios a serem superados envolvem 0 controle do processo.

Natalaense (2013) afirma que fabricação de biobutanol pode ser uma oportunidade para as usinas de açucareiras diversificarem sua produção, uma vez que os substratos utilizados para o processo são basicamente os mesmos. Atualmente as usinas já contam com a flexibilidade de produzir açúcar e álcool e poderiam incorporar a opção de produzir butanol, ou ainda, e em um futuro próximo, após o desenvolvimento de processos de pré-tratamento e hidrólise, poderiam implantar biorrefinarias para produção de combustíveis de segunda geração utilizando como matéria prima os resíduos da indústria. A perspectiva é que o Brasil deixe de ser um país importador de n-butanol e se torne um país exportador de n-butanol com a adoção dos processos fermentativos, sendo que inicialmente o mercado será domestico e relacionado à produção de químicos, e em uma fase posterior, o país poderá se tornar um exportador de biobutanol.

\section{CONCLUSÃO}

Com os dados apresentados neste trabalho é possível afirmar que biobutanol vem se destacando como um promissor biocombustível, por apresentar características muito próximas a gasolina, sendo por isso, tratado como uma promessa no setor energético, tanto em relação as questões ambientais, quanto em relação a dependência das flutuações do setor petroquímico.

Já existem empresas que aplicam processos tecnológicos para produção de biobutanol, entretanto ainda são necessários muitos avanços em termos de matéria prima, engenharia genética e biorreatores para que a produção atinja o patamar desejado. Caso o processo fermentativo seja aprimorado, o 
biobutanol pode se tornar um promissor substituto par a gasolina.

As pesquisas indicaram que o Brasil pode ser um dos pioneiros na produção do biobutanol, uma vez que já é capaz de produzir em escala industrial bioetanol e biodiesel, possuir as matérias primas e agentes biológicos necessários.

\section{REFERÊNCIAS}

ANDRADE, J.C.; VASCONCELOS, I. 2003.Continuous cultures of Clostridium acetobutylicum: culture stability and lowgradeglycerolutilisation. Biotechnol.Lett. 25, 121-125.

BALAT, M; BALAT, H.Recent trends in global production and utilization of bioethanol fuel. Applied Energy, n. 86, p. 2.2732.282, 2009.

BARCELOS, C. Aproveitamento das frações sacarínea, amilácea e lignocelulósica do sorgo sacarino[Sorghum bicolor (L.) Moench] para a produção de bioetanol.2012, Tese (doutorado em Tecnologia de Processos Químicos e Bioquímicos)- Universidade Federal do Rio de Janeiro, Escola de Química. Rio de Janeiro-RJ, 2012.

BADR,HR;TOLEDO,R;HAMDY,MK.Contin uousacetoneethanol butanol fermentationbyimmobilizedcellsof Clostridium acetobutylicum.BiomassBioenergy. 2001,20:119-132

BOHLMANN, G; BRAY, R. Biobutanol. Report n. 264, ProcessEconomicProgram, SRI Consulting, Dezembro 2008.
BOHLMANN, G. Biobutanol.Process Economic Program, review 2007-1, SRI Consulting, Maio 2007.

BORSCHIVER, S. Analisando a Dinâmica do Mercado de Biocombustíveis. 7th Biodiesel Congress, 27 a 29 de Julho de 2011.

BORZANI,W.;SCHMIDELL,W.;LIMA,U.A.; AQUARONE,E.BiotecnologiaIndustrial:En genharia Bioquimica.Vol.3. São Paulo:

Edgard Blucher,2001.

\section{CASCONE, R.N.Biobutanol: A}

Replacement for Bioethanol?,SBE Special Section I - Biofuels, Society of Biological Engineering, pp. 1-9, 2009.

CGEE - Centro de Gestão e Estudos Estratégicos. Bioetanol combustível, uma oportunidade para o Brasil, 2009.

CHANDEL, A.K; KAPOOR, R.K; SINGH, A; KUHAD, R.C. Detoxification of sugarcane bagasse hydrolysate improves ethanol production by Candida shehatae NCIM 3501. Biores. Technol. 98:1947-1950, 2007.

CLAASSEN,P;BUDDEMAW,AM;LÓPEZCONTRERAS,AM. Acetone, butanol and ethanolproduction from domestic organic waste by solventogenic clostridia. $\mathrm{J}$ MolMicrob Biotech.2000, 2(1): 39-44.

ELLIS, J.T; HENGGE, N.N; SIMS, R.C;MILLER, C.D. 2012. Acetone,butanol, and ethanol production from wastewater algae.Bioresour. Technol. 111, 491-495.

EVANS, PJ; WANG, HY.Enhancement of butanol formation by Clostridium acetobutylicumin the presence of decanololeyl alcohol mixed extractants. Appl Environ Microbiol.1988, 54:1662 - 1667.

EZEJI, T; BLASCHEK, HP. Fermentation of dried distillers' grains and solubles (DDGS) hydrolysates to solvents and value-added products by solventogenic clostridia.Bioresource Technol. 2008, 99(12): 5232-5242. 
EZEJI, TC; QURESHI, N; BLASCHEK, HP. Acetone butanol ethanol (ABE) production from concentrated substrate: reduction in substrate inhibition by fed-batch technique andproduct inhibition by gas stripping.ApplMicrobiolBiotechnol. 2004a, 63:653-8.

EZEJI, TC;QURESHI, N; BLASCHEK, HP. Butanol fermentation research:Upstreamanddownstream manipulations. Chem Rec. 2004b, 4:305 314.

EZEJI, T.C;QURESHI, N; BLASCHEK, H.P. 2007. Production of acetone butanol (AB) from liquefied corn starch, a commercialsubstrate, using Clostridium beijerinckiicoupled with productrecovery by gas stripping. J. Ind. Microbiol. Biotechnl. 34,771-777.

FRANCO,L.A gasolina do futuro: Brasil investe na pesquisa e produção de biobutanol, um combustível avançado que deve começar a ser exportado em três anos.2015. RevistaGlobo Rural. São Paulo,2015.

GARCÍA,V;PÄKKILÄ,J;OJAM,H;MUURIN EN,E;KEISKI,R. Challenges in biobutanol production: How to improve the efficiency?.Renewable and Sustainable Energy Reviews 15 (2011) 964-980.

GEVO, Isobutanol - a renewable solution for the transportation fuel value chain.Gevo White Paper, Maio 2011.

GROOT, W.J;OEVER, C.E; VAN, D; KOSSEN, N.W.F. Pervaporation for simultaneous productrecovery in the butanol/isobutanol batch fermentation. BiotechnolLett.1984, 6:709 - 714 .

GRZENIA, DL;SCHELL, DJ;WICKRAMASINGHE, S.R. Membrane extraction for detoxification of biomass hydrolysates. Bioresource Technol. 2012, 111:248-254.
JIN, C; YAO, M; LIU, H; F.LEE, C; Progress in the production and application of $n$ butanol as a biofuel,2011. Renewable and Sustainable Energy Reviews, 15, 4080-4106.

JONES, D. T; WOODS, D. R. AcetoneButanol Fermentation.Revisited.

Microbiological Reviews, v. 50,p. 484-524, 1986.

KUMAR, M; GAYEN, K; Developments in biobutanol production: New insights Applied Energy 88 (2011) 1999-2012.

LEE, S. Y; PARK, J. H;JANG, S. H; NIELSEN, L. K; KIM, J; JUNG, K. S. 2008. Fermentative butanol production by Clostridia.Biotechnology and bioengineering, 101(2), 209-228.

LIU, H;WANG, G;ZHANG, J. 2013. The Promising Fuel-Biobutanol.INTECH Open Access Publisher.

LIEW, S.T; ARBAKARIYA, A; ROSFARIZAN, M; RAHA, AR. Production of solvent (acetonebutanol-ethanol) in continuous fermentation by Clostridium saccharobutylicum DSM13864 using gelatinised sago starch as a carbon source. 2005. Malays J Microbiol. 2005, 2(2):42 - 45

MAGALHÃES,B. Otimização da produção de butanol por cepas de clostridiumspp. Utilizando hidrolisado lignocelulósico.2015, Tese (mestrado em Genética e Biologia Molecular)-Universidade Estadual de Campinas. São Paulo,2015.

MARIANO, A.P; QURESCHI, N; MACIEL FILHO, R; EZEHI, T.C. Assessmentofin situ butanol recoverybyvacuumduringacetone butanol etanol (ABE) fermentation .J. Chem. Technol. Biotechnol. 2012, 87: 334340 .

MAITI, S;SARMA, S. J; BRAR, S. K; LE BIHAN, Y; DROGUI, P; BUELNA, G; VERMA, M. 2016. Agro-industrial wastes as feedstock for sustainable bio-production of butanol by Clostridium 
beijerinckii. Food and Bioproducts

Processing, 98, 217-226.

MASCAL, M.Chemicals from biobutanol: technologies and markets. Biofuels, Bioprod. Bioref. 6:483-493 (2012).

NATALAENSE,J. Prospecção tecnológica de biobutanol no contexto brasileiro de biocombustíveis.2013.126f.Tese(Mestrado em tecnologia nuclear)-Instituto de pesquisas energéticas e nucleares,Universidade de São Paulo,São Paulo.2013.

NEJAME, S.Butanol as a Fuel - View from the field. Promotum, presentation to NREL, Março 11th, 2010.

NIEMISTÖ, J; SAAVALAINEN, P; PONGRÁCZ, E; KEISKI, R.L. Biobutanol as a Potential Sustainable Biofuel Assessment of Lignocellulosic and Wastebased Feedstocks, J. sustain. dev. energy water environ. syst., 1(2), pp 58-77, 2013.

OUDSHOORN,A; VAN DER, WIELEN LAM; STRAATHOF, AJJ. Assessment of optionsfor selective 1-butanol recovery from aqueous solutions.2009.IndEngChemRes, 2009;48:732 5-36.

PARRELLA, R. A;MENEGUCI, J. L; RIBEIRO, A; SILVA, A. R. PARRELLA, N., RODRIGUES, J. D. S.,\& Pesquisadora, E. 2010. Desempenho de cultivares de sorgo sacarino em diferentes ambientes visando a produção de etanol. In Congresso Nacional de Milho e Sorgo (Vol. 28).

QUILHÓ,L. Produção de Bioetanol a partir de Materiais Lenho-celulósicos de Sorgo Sacarino:Revisão

Bibliográfica.2011, Tese(mestrado em Energia e Bioenergia)-Faculdade de Ciencias e Tecnologia e Universidade Nova de Lisboa. Caparica, Portugual.2011.

QURESHI, N; EZEJI,TC; EBENER, J;DIEN, BS; COTTA, MA; BLASCHEK, HP. Butanol productionby Clostridium beijerinckii.

Part I: use of acid and enzyme hydrolyzed corn fiber.BioresourseTechnol.2008, 99:5915 - 5922.

QURESHI, N; HUGHES, S;MADDOX, IS; COTTA, MA. Energy efficient recovery of1butanol from model solutions and fermentation broth by adsorption.Bioprocess BiosystEng 2005;27:215-22.

QURESHI,N;MEAGHER,MM;HUTKINS,R $\mathrm{W}$. Recovery of butanol from model solutions and fermentation broth using a silicalite silicone membrane. J MembranE Sci. 1999,158(1-2): 115-125.

QURESHI, N; SAHA, BC; DIEN, B;HECTOR ,RE; COTTA, MA. Production of butanol (a biofuel)from agricultural residues: part I-use of barley straw hydrolysate. Biomass Bioenerg.2010a, 34:559- 565 .

QURESHI, N; SAHA, BC;HECTOR, RE;DIEN, B;HUGHES, S; LIU,S; ITEN, L; BOWMAN, MJ; SARA,THG;COTTA,MA. Production of butanol (a biofuel) from agricultural residues: part II -use of corn stover and switchgrasshydrolysates.

BiomassBioenerg. 2010b, 35:559 - 669 .

RABELO,S. Avaliação e otimização de prétratamentos e hidrólise enzimática do bagaço de cana-de-açúcar para a produção de etanol de segunda geração.

2010.Disponível em $<$ http://www.bibliotecadigital.unicamp.br/docu ment $/$ ?code $=000770600>$. Acesso em: junho de 2016.

RAGANATIA,F;CURTHB,S;GÖTZB,P;OIVI ERIA,G;MARZOCCHELLAA,A.2012.Buta nol production from lignocellulosic-based hexoses and pentoses by fermentation of clostridium acetobutylicum. Chemical Engineering Transactions, 27,91-96 DOI:10.3303/CET1227016.

RANJAN, A; MOHOLKAR, V.S.

Biobutanol: science, engineering, and 
economics .Int. J. Energy Res. 2012; 36: 277 323.

RODRIGUES, J.A.R., Do Engenho à

Biorrefinaria. A Usina de Açúcar como

Empreendimento Industrial para a

Geração de Produtos Bioquímicos e

Biocombustíveis, Quim. Nova, Vol. 34, n. 7, 1245-1254, 2011.

SOUZA,C.Produção de etanol por sacarificação e fermentação simultâneas do bagaço de cana-de-açúcar utilizando leveduras termotolerantes. 2011, Tese (mestrado em Microbiologia Agrícola) Universidade Federal de Viçosa. Viçosa, 2011.

SOUZA, A. M. G. F.. Efeito da adição de butanol na biodegradabilidade da gasolina e do diesel, Dissertação (Graduação), Universidade Estadual Paulista, Instituto de Geociências e Ciências Exatas, Rio Claro, 2009.

SONI, BK; DAS, K;GHOSE, TK.

Bioconversion of agro-wastes into acetone butanol. BiotechnologyLetters. 1982, 4(1):19-22.

SUN, ZJ;LIU, SJ. Production of n-butanol from concentrated sugar maple hemicellulosic hydrolysate by Clostridia acetobutylicum ATCC824. BIOMASS \& BIOENERGY.2012, 39(SI):39-47.

TRAN,HTM;CHEIRSILP,B;HODGSON,B; UMSAKUL,K.Potectial use of Bacillus subtilis in aco-culture with Clostridium butylicum for acetone-butanol-ethanol production fromcassava starch.

2010.Biochem Eng. 2010, 48:260 - 267

VILLELA FILHO, M; ARAUJO, C; BONFÁ, A; PORTO, W.Chemistry Based on

Renewable Raw Materials: Perspectives for a Sugar-Cane Based Biorefinery, Enzyme Research, Article ID 654596, 2011.

VISIOLI,L. Avaliação da produção biotecnológica de butanol a partir de sorgo sacaríneo.2014, Tese (Mestrado em Engenharia de Processos)- Universidade Federal de Santa Maria,Santa Maria, RS,2014.

WANG, L; CHEN, HZ.Increased fermentability of enzymatically hydrolyzed steam-explodedcornstover for butanol production by removal of fermentation inhibitors.2011.Process Biochem. 2011, 46(2):604-607. 